\title{
O PROCESSO DE DESCENTRALIZAÇÃO E O FINANCIAMENTO DAS POLÍTICAS PÚBLICAS EDUCACIONAIS
}

\author{
THE DECENTRALIZATION PROCESS AND THE FINANCING OF PUBLIC EDUCATIONAL
}

EL PROCESO DE DESCENTRALIZACIÓN Y FINANCIAMIENTO DE LA POLÍTICA DE LA EDUCACIÓN PÚBLICA

\author{
TEIXEIRA, lara da Paixão Corrêa ${ }^{1}$ \\ NUNES, André2
}

ALMEIDA, Alexandre Nascimento de ${ }^{3}$

\begin{abstract}
RESUMO
O artigo tem como objetivo compreender o processo de descentralização de recursos para fins de financiamento de políticas públicas educacionais e o impacto da política na melhoria da qualidade do ensino, medida pelo IDEB. A pesquisa teve como base teórica artigos relacionados ao processo de descentralização de políticas públicas e a legislação a respeito do financiamento educacional, em especial as leis que instituíram o FUNDEF e o FUNDEB. Os dados apontam que a política dos Fundos aumentou a capacidade de investimento sem, no entanto, proporcionar uma melhoria significativa na qualidade do ensino público nos municípios do Território das Águas Emendadas.
\end{abstract}

Palavras-chave: Descentralização. Política pública educacional. Financiamento educacional.

\section{ABSTRACT}

The article aims to understand the features of the decentralization process for the financing of public educational policies and the impact of the policy on improving the quality of education, as measured by IDEB. The research was theoretical base articles related to the process of decentralization of public policies and legislation regarding educational funding, especially the laws that established FUNDEF and FUNDEB The Data indicate that the policy of the Funds increased investment capacity without, however ,providing a significant improvement in the quality of public education in the federal entities of the Emendadas Waters.

Keywords: Descentralization. Education public policy. Financiamento educacional.

\section{RESUMEN}

El artículo tiene como objetivo comprender las características del proceso de descentralización de la financiación de las políticas educativas y el impacto de la política de mejora de la calidad de la educación, medida por IDEB. La investigación fue de artículos de la base teóricos relacionados con el proceso de descentralización de las políticas públicas y legislación en materia de financiación educativa, especialmente las leyes que establecieron FUNDEF y FUNDEB. Los datos indican que la política de los Fondos aumentó la capacidad de inversión, sin embargo, proporciona una mejora significativa en la calidad de la educación pública en los municipios del territorio de Aguas Emendadas.

Palabras clave: Descentralización. Política de la educación pública. Financiación de la educación.

\footnotetext{
1 Universidade de Brasília - UNB - Brasília - Brasil

2 Universidade de Brasília - UNB - Brasília - Brasil

3 Universidade de Brasília - UNB - Brasília - Brasil
} 


\section{INTRODUÇÃO}

O presente artigo tem como temática central a compreensão do processo de descentralização na política de financiamento da educação brasileira e o impacto dessa política na qualidade do ensino, medida pelo Índice de Desenvolvimento da Educação Básica - IDEB nos entes federados pertencentes ao Território das Águas Emendadas, tendo como recorte temporal os anos de 2005 a 2014 . A delimitação em torno do Território das Águas Emendadas se justifica pela carência de pesquisas voltadas ao universo pertencente a uma política territorial ainda em desenvolvimento no Brasil.

A realização da análise pretendida teve como embasamento pesquisa bibliográfica em torno da temática da descentralização de políticas públicas ocorridas em especial após a redemocratização do Estado brasileiro e análise da legislação relacionada ao financiamento e qualidade do ensino. Assim, as legislações que subsidiaram a compreensão sobre o financiamento educacional brasileiro foram: a Lei de Diretrizes e Bases da Educação Nacional - LDB e as leis que instituíram o Fundo de Manutenção e Desenvolvimento do Ensino Fundamental e de Valorização do Magistério - FUNDEF e o Fundo de Manutenção e Desenvolvimento da Educação Básica e de Valorização dos Profissionais da Educação - FUNDEB.

O impacto do processo de descentralização das políticas públicas educacionais sobre o financiamento e a qualidade do ensino foi verificado utilizando-se como parâmetro a nota atingida no Índice de Desenvolvimento da Educação Básica - IDEB, em relação à estipulada para a municipalidade.

O objetivo principal deste artigo é verificar se as despesas com a educação foram capazes de impactar na melhoria da qualidade do ensino medida por meio do IDEB, no Território das Águas Emendadas, nos anos de 2005 a 2014. Ainda teve como pretensão analisar as notas atingidas pelos entes pesquisados e verificar se os mesmos tem melhorado a qualidade do ensino mediante a crescente demanda de recursos para a educação básica, principalmente após o advento do FUNDEF e FUNDEB.

Dessa forma este artigo está estruturado em cinco partes principais. A primeira faz uma pesquisa bibliográfica em torno do processo de descentralização. Na segunda e na terceira parte, é realizado um estudo sobere a política dos fundos de financiamento educacional, o FUNDEF e o FUNDEB. A parte seguinte trata da metodologia utilizada para a construção deste artigo e como foram coletados os dados necessários para a verificação do impacto do financiamento educacional brasileiro na melhoria do ensino. A quinta parte traz a discussão dos resultados fazendo uma comparação entre as despesas empenhadas no Ensino Fundamental, com o número de alunos matriculados e a nota do IDEB atingida, tanto nas séries iniciais quanto nas finais, buscando assim verificar se o investimento em educação está alcançando melhores índices nas avaliações do IDEB.

Espera-se que este trabalho contribua para que outras reflexões acerca da gestão dos recursos disponibilizados à educação básica sejam realizadas. 


\section{O PROCESSO DE DESCENTRALIZAÇÃO NAS POLÍTICAS PÚBLICAS EDUCACIONAIS}

A redemocratização que ocorreu no Brasil no final dos anos 80 e a promulgação da Constituição Federal de 1988 introduziram a ampliação dos direitos sociais, a universalização do acesso aos serviços públicos e a descentralização da prestação desses serviços para os estados e municípios, como resultado do pacto federativo. Outra consequência do pacto federativo foi a criação de uma nova estrutura de repartição de recursos tributários que são os responsáveis pela criação das receitas que financiam a implantação de políticas públicas sociais para atendimento da população (GRAEF, 2010).

Com a descentralização houve uma forte mudança na agenda de responsabilidades para os municípios. Responsabilidades que antes eram de competência estadual e federal passaram à esfera municipal. Dessa forma, a descentralização está inserida dentro de um contexto marcado pela disputa da formação e definição da agenda (ARRETCHE, 1996).

A descentralização está, por um lado, intrínseca à concepção neoliberal de Estado mínimo. Nesse contexto, cabe ao estado privatizar a provisão de bens públicos e ao governo central descentralizar os serviços a fim de garantir maior eficiência. Por outro lado, a descentralização tem como missão promover a redistribuição de poder, favorecendo a democratização das relações entre Estado e sociedade (FARAH, 2001).

A elevação da importância da ação municipal é consequência direta do processo de descentralização. De acordo com Farah (2001), esse novo arranjo institucional da federação gerou vários desdobramentos, surgindo a necessidade de desenhos de políticas municipais integradas para serem mais efetivas no atendimento de um mesmo público alvo, a articulação com atores da sociedade civil, com outros municípios (consórcios intermunicipais) e os governos locais assumindo uma postura de coordenação e de mobilização de governos e organizações não governamentais em prol de atender às diversas demandas de seu território.

No Brasil, o foco da descentralização perpassa pela descentralização fiscal e pelas políticas sociais nas áreas de educação, saúde e assistência social. Uma marca da descentralização na Constituição Federal, no campo educacional, se refere à repartição de competências, também previstas no artigo 211. De acordo com esse dispositivo, os municípios têm atuação prioritária na educação infantil e no ensino fundamental enquanto, que os estados, atuarão, prioritariamente, no ensino fundamental e médio (BRASIL, 1988).

A Constituição Federal de 1988 vinculou parcela de receitas fiscais das três esferas de governo, municipal, estadual e federal, à manutenção e desenvolvimento do ensino. Essa medida, logo que implantada, evidenciou as distorções e disparidades existentes no território brasileiro quanto à capacidade dos entes em arcar com suas responsabilidades constitucionais e sinalizou os grandes desníveis no desenvolvimento econômico existente entre as regiões (GRAEF, 2010).

Para minimizar essas disparidades regionais e garantir a universalização de uma educação de qualidade a todos foi criado o FUNDEF, que posteriormente foi substituído pelo FUNDEB. 


\title{
O FUNDO DE MANUTENÇÃO E DESENVOLVIMENTO DO ENSINO FUNDAMENTAL E DE VALORIZAÇÃO DO MAGISTÉRIO - FUNDEF
}

Dentre os esforços voltados para a política de financiamento da educação no Brasil no período pós-Constituição, destaca-se a criação, pela Lei $n^{\circ}$ 9.424/96, do Fundo de Manutenção e Desenvolvimento do Ensino Fundamental e de Valorização do Magistério - FUNDEF. Sua implantação se deu em $1^{\circ}$ de janeiro de 1998, quando passou a vigorar em todo o país, exceto no Pará, onde a implantação ocorreu em julho de 1997, por força de lei estadual nesse sentido (BRASIL, 2004).

O Manual de Orientações do FUNDEF destaca que o fundo mudou a estrutura de financiamento da educação brasileira:

\begin{abstract}
A maior inovação do FUNDEF consistiu na mudança da estrutura de financiamento do Ensino Fundamental Público no País, pela subvinculação de uma parcela dos recursos da educação a esse nível de ensino, com distribuição de recursos realizada automaticamente, de acordo com o número de alunos matriculados em cada rede de ensino fundamental, promovendo a partilha de responsabilidades entre o Governo Estadual e os Governos Municipais. (BRASIL, 2004, p.7).
\end{abstract}

A confirmação a respeito da inovação introduzida pelo FUNDEF é corroborada por Castro (2007) ao afirmar que esse Fundo trouxe uma nova forma de repartição dos recursos para o ensino fundamental uma vez que estipulou uma equalização do valor do gasto por aluno/ano com base no indicador educacional matrícula.

Segundo afirma Amaral (2001, p. 208), o FUNDEF é "constituído em cada estado e o efeito provocado pela sua constituição é o de redistribuir recursos dentro do próprio estado." Acrescenta ainda que o Fundo instituído "retira os recursos de alguns municípios e os remete a outros, de tal modo que uniformiza em todo o estado, o valor gasto por estudante do ensino fundamental".

Como a metodologia de distribuição dos recursos do FUNDEF era proporcional ao número de alunos matriculados no ensino fundamental em cada rede de ensino, estadual ou municipal, acabou-se por criar um incentivo para que os municípios incorporassem mais alunos à sua rede de ensino a fim de aumentar os recursos destinados aos municípios. Dessa forma, o FUNDEF contribuiu para que ocorresse a municipalização da oferta de vagas no ensino fundamental (VELOSO, 2009).

Outra análise a respeito da distribuição das responsabilidades pela educação básica no Brasil após a criação do FUNDEF foi realizada por Pinto (2007) tendo por base os dados do Censo Escolar do Instituto Nacional de Estudos e Pesquisas Educacionais - INEP. Segundo aponta esse autor, o FUNDEF é o principal fator responsável por esta mudança no perfil de atendimento educacional no país tendo em vista que a parcela dos recursos vinculados à educação foi atrelada à quantidade de alunos matriculados no ensino fundamental regular.

$\mathrm{Na}$ reflexão em torno do importante papel desempenhado pelo FUNDEF na expansão do ensino fundamental, Veloso (2009) assegura que se tratava de um fundo destinado exclusivamente a essa etapa da educação básica. No entanto, após os dez anos de sua vigência, surgiu a necessidade 
de distribuição de recursos para atender os alunos concluintes do ensino fundamental que necessitavam ser atendidos nas escolas da rede pública para continuar seus estudos. Assim, o mecanismo de distribuição de recursos do FUNDEF passou a criar dificuldades para a expansão do ensino médio.

Para corrigir essas distorções foi instituído o Fundo de Manutenção e Desenvolvimento da Educação Básica e de Valorização dos Profissionais da Educação - FUNDEB (VELOSO, 2009).

\section{O FUNDO DE MANUTENÇÃO E DESENVOLVIMENTO DA EDUCAÇÃO BÁSICA E DE VALORIZAÇÃO DOS PROFISSIONAIS DA EDUCAÇÃO - FUNDEB}

Na definição trazida pelo Manual de Orientação do FUNDEB (2008), o Fundo de Manutenção e Desenvolvimento da Educação Básica e de Valorização dos Profissionais da Educação - FUNDEB, instituído pela Lei no 11.494/2007, é um Fundo de natureza contábil, constituído em cada estado da federação, formado por parcela financeira de recursos federais e por recursos provenientes dos impostos e das transferências dos Estados, Distrito Federal e Municípios vinculados à educação por força do disposto no art. 212 da Constituição Federal. Independentemente da fonte de origem, todo o recurso gerado é redistribuído para aplicação exclusiva na educação básica (BRASIL, 2008a).

Os recursos do FUNDEB devem ser empregados exclusivamente em ações de manutenção e de desenvolvimento da educação básica pública, particularmente na valorização do magistério. Dessa forma, uma parcela mínima de $60 \%$ do Fundo deve ser destinada à remuneração dos profissionais do magistério em efetivo exercício na educação básica pública e o total de até $40 \%$ restantes devem ser direcionados para despesas diversas consideradas como de Manutenção e Desenvolvimento do Ensino - MDE (BRASIL, 2007).

Para as despesas consideradas como Manutenção e Desenvolvimento do Ensino -MDE deve ser observado o disposto no artigo 211 da Constituição Federal que estabelece a atuação prioritária aos municípios, no ensino fundamental e na educação infantil, e aos Estados e Distrito Federal, no ensino fundamental e médio (BRASIL, 1988).

No caso do Distrito Federal, o Manual de Orientação do FUNDEB (2008), traz a responsabilização para com as despesas de MDE referentes à educação infantil, ao ensino fundamental e ao ensino médio para esse ente federado. Dessa forma, o Distrito Federal exerce duplamente a natureza de município e estado (BRASIL, 2008a).

O monitoramento de aplicação dos recursos do FUNDEB é realizado por meio da utilização do Sistema de Informações sobre Orçamento Público em Educação - SIOPE e do estabelecimento de parcerias, em regime de cooperação, com os Tribunais de Contas dos estados e/ou dos municípios (BRASIL, 2008b).

Em que pese os avanços que o novo Fundo trouxe para ao financiamento educacional, há críticas e questionamentos acerca de outros aspectos envolvendo o FUNDEB, principalmente aqueles 
relacionados ao total de recursos provenientes da complementação da União, que é interpretado como insuficiente, e ainda, ao fato de não abranger a ideia do valor mínimo a ser investido para se obter a melhoria da qualidade do ensino (AMARAL, 2012).

\section{METODOLOGIA}

Para analisar o processo de descentralização dos recursos educacionais, o recorte temporal compreendeu o período de 2005 a 2014. Quanto à limitação dos entes federativos, utilizou-se o Território das Águas Emendadas como unidade de análise. De acordo com o Ministério do Desenvolvimento Agrário - MDA, o Território das Águas Emendadas possui 2.898.988 habitantes e abrange uma área de $37.721,70 \mathrm{Km}^{2}$. É composto por 11 municípios dos estados de Goiás, Minas Gerais e o Distrito Federal, a saber: Água Fria de Goiás, Cabeceiras, Formosa, Mimoso de Goiás, Padre Bernardo, Planaltina, Vila Boa, Brasília, Buritis, Cabeceira Grande e Unaí.

Com o objetivo de verificar a relação entre o investimento em educação para os entes do Território das Águas Emendadas e a qualidade da educação, foi considerado o IDEB como um indício de qualidade. Nesse sentido, Gouveia, Souza e Tavares (2009, p.47) afirmam que "o Ideb é um instrumento que pode dimensionar, mesmo que em parte, a efetividade das políticas educacionais".

De acordo com o Instituto Nacional de Estudos e Pesquisas Educacionais Anísio Teixeira INEP, o IDEB é um indicador de qualidade educacional que aborda informações de desempenho em exames padronizados obtido pelos estudantes ao final das etapas de ensino com informações sobre rendimento escolar. Dessa forma, o IDEB é o resultado do produto entre o desempenho e do rendimento escolar (ou o inverso do tempo médio de conclusão de uma série).

Do sítio do INEP foram extraídas as notas do IDEB nos anos de 2005, 2007, 2009, 2011 e 2013, em que são consideradas as avaliações para a composição do índice, pois este é aferido a cada dois anos. Como a pesquisa está delimitada à modalidade Ensino Fundamental, foi considerada a nota atingida pelos estudantes concluintes dessa etapa da Educação Básica. Tal delimitação com relação aos alunos concluintes do Ensino Fundamental se deve ao fato de que de acordo com a Constituição os municípios atuarão prioritariamente na Educação Infantil e no Ensino Fundamental. Dessa forma, a realidade da distribuição de responsabilidades com a educação atende ao disposto na Carta Magna, sendo que na prática na maioria dos casos as escolas de Ensino Fundamental estão a cargo das municipalidades.

Para avaliar o impacto do financiamento educacional nas notas do IDEB, indicador que mensura a qualidade da educação básica, essa pesquisa se valeu de dados relacionados à despesa empenhada para a educação se limitando ao Ensino Fundamental.

Dessa forma, o Fundo Nacional de Desenvolvimento da Educação - FNDE, por meio do Sistema de Informações sobre Orçamento Público em Educação - SIOPE, disponibilizou os dados relacionados aos gastos com a função Educação, de onde pode ser trabalhado o filtro para que se 
pudesse obter os gastos somente com a modalidade Ensino Fundamental para os municípios pertencentes ao Território das Águas Emendadas.

Ainda é importante ressaltar que a coleta de dados relacionados às despesas empenhadas no Ensino Fundamental para os municípios pesquisados se deu nos anos de 2005 a 2014, tendo como base a declaração que cada unidade da federação informou ao FNDE por meio do SIOPE. Foi realizada ainda a coleta anual dos alunos declarados no censo escolar nos anos de 2005 a 2014, com base em dados também extraídos do SIOPE.

\section{DISCUSSÃO DOS RESULTADOS}

A análise dos dados tem como ponto de partida o ano de 2005, ano em que se iniciou a aferição do IDEB pelo INEP. Para a comparação desse indicador foram extraídas as notas atingidas nos anos iniciais ( $4^{\mathrm{a}}$ série $/ 5^{\circ}$ ano) e nos anos finais ( $8^{\mathrm{a}}$ série $/ 9^{\circ}$ ano) do Ensino Fundamental nos municípios do Território das Águas Emendadas e no Distrito Federal.

A Tabela 1 - IDEB observado: Anos Iniciais e Finais do Ensino Fundamental apresenta os resultados do IDEB nos anos considerados (2005 a 2013) nos entes que integram o Território das Águas Emendadas.

Tabela 1 - IDEB Observado: Anos Iniciais e Finais do Ensino Fundamental

\begin{tabular}{|c|c|c|c|c|c|c|c|c|c|c|}
\hline \multirow{2}{*}{$\begin{array}{c}\text { Ente Federado do Território } \\
\text { das Águas Emendadas }\end{array}$} & \multicolumn{5}{|c|}{$\begin{array}{c}\text { IDEB - Anos Iniciais do Ensino } \\
\text { Fundamental }\end{array}$} & \multicolumn{5}{|c|}{$\begin{array}{c}\text { IDEB - Anos Finais do Ensino } \\
\text { Fundamental }\end{array}$} \\
\hline & 2005 & 2007 & 2009 & 2011 & 2013 & 2005 & 2007 & 2009 & 2011 & 2013 \\
\hline Água Fria de Goiás/GO & 3,6 & 4,4 & 3,9 & 4,0 & 5,4 & - & - & - & - & - \\
\hline Cabeceiras/GO & - & 3,2 & - & 4,3 & 4,2 & - & - & - & - & - \\
\hline Formosa/GO & 4,1 & 4,3 & 4,7 & 4,9 & 4,9 & 4,0 & 4,1 & 4,2 & 3,9 & 4,2 \\
\hline Mimoso de Goiás/GO & - & 3,9 & 4,2 & 4,3 & 4,5 & - & - & - & - & - \\
\hline Padre Bernardo/GO & 3,3 & 3,3 & 3,8 & 4,2 & 4,9 & 3,0 & 3,1 & 3,4 & 3,6 & 3,9 \\
\hline Planaltina/GO & 3,4 & 3,5 & 3,7 & 4,2 & 4,4 & 3,1 & 3,2 & 3,4 & 3,4 & 3,5 \\
\hline Vila Boa/GO & 4,1 & 3,5 & 3,6 & 4,0 & 4,3 & - & 3,7 & 4,0 & 4,6 & 4,1 \\
\hline Brasília/DF & 4,4 & 4,8 & 5,4 & 5,4 & 5,3 & 3,3 & 3,5 & 3,9 & 3,9 & 3,8 \\
\hline
\end{tabular}




\begin{tabular}{|l|c|c|c|c|c|c|c|c|c|c|}
\hline Buritis/MG & 3,5 & 3,8 & 4,5 & 4,7 & 5,6 & 3,1 & 4,0 & 4,2 & 4,0 & 4,4 \\
\hline Cabeceira Grande/MG & - & 3,6 & 4,0 & 4,8 & 5,3 & - & 3,1 & 3,4 & 3,4 & 3,8 \\
\hline Unaí/MG & 4,2 & 4,3 & 4,6 & 5,1 & 5,3 & 3,7 & 3,8 & 4,0 & 4,2 & 4,1 \\
\hline
\end{tabular}

Fonte: Saeb e Censo Escolar. (adaptado pelos autores). As notas em destaque referem-se ao IDEB atingido.

A partir deste ponto do artigo serão apresentados os dados relacionados à despesa empenhada no Ensino Fundamental para os entes pertencentes ao Território das Águas Emendadas analisando o investimento nessa etapa da educação básica e a nota atingida no IDEB em relação àquela estipulada para o município, conforme Tabela 1.

Observa-se com base nos dados apresentados no Gráfico 1 que o município de Água Fria de Goiás tem elevado consideravelmente o seu investimento no Ensino Fundamental. No ano de 2005 foram empenhados $\mathrm{R} \$ 1.229 .728,02$ para as despesas com o Ensino Fundamental e, no ano de 2014, $\mathrm{R} \$ 4.084 .262,06$. Conclui-se que o investimento mais que triplicou em menos de 10 anos.

Gráfico 1 - Despesa empenhada e matrículas no EF no município de Água Fria de Goiás - GO

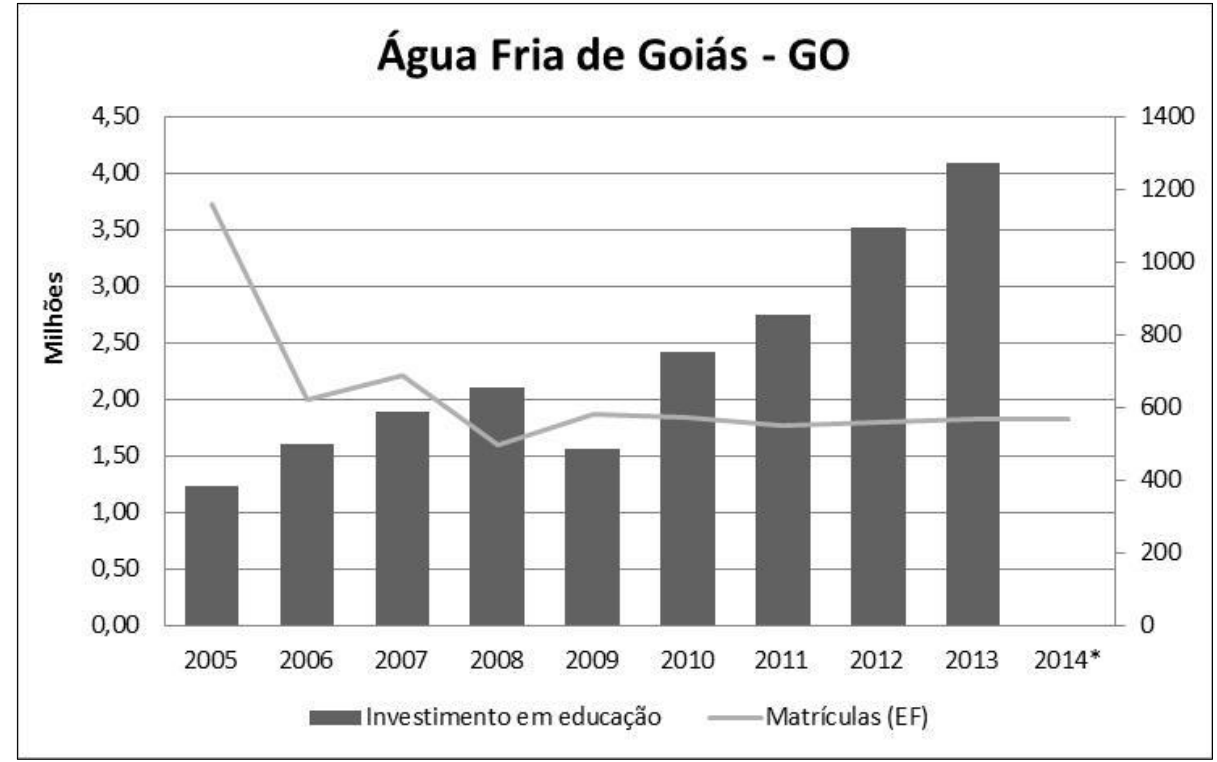

Fonte: SIOPE/FNDE (elaborado pelos autores).

Por outro lado, o número de matrículas caiu de 1.157, em 2005, para 569, em 2013. Os dados apontam que o município ampliou consideravelmente o investimento no ensino fundamental, ponderando que as matrículas nessa etapa da educação básica têm comportamento decrescente e o investimento, por sua vez, apresenta comportamento crescente. 
Estabelecendo a comparação com o desenvolvimento do município no quesito qualidade do ensino medido pelo IDEB, observa-se que no ano de 2013 a nota do IDEB foi 5,4 e a meta foi atingida. No entanto, o mesmo comportamento descrito acima pode ser observado para os anos anteriores e a meta do IDEB não foi atingida. Ressalta-se que o município de Água Fria de Goiás não informou os dados do ano de 2014 ao SIOPE. O prazo legal para a entrega da declaração é 30 de abril do ano seguinte ao exercício informado.

Com relação ao município goiano de Cabeceiras, observa-se que o número de matrículas no Ensino Fundamental caiu consideravelmente do ano de 2005 para 2006, tendo um comportamento ascendente nos anos seguintes. Verifica-se ainda, pela análise do Gráfico 2, que o investimento nessa etapa da educação básica tem aumentado.

Observando a nota obtida no IDEB para os anos iniciais do Ensino Fundamental (nos anos finais não há dados disponíveis) constata-se que, embora o município tenha atingindo a meta, trata-se de uma meta muito baixa se comparado a outros entes federados. Obteve-se a nota 4,3 em 2011, e em 2013 caiu para 4,2; conforme se observa na Tabela 1.

Gráfico 2 - Despesa empenhada e matrículas no EF no município de Cabeceiras - GO

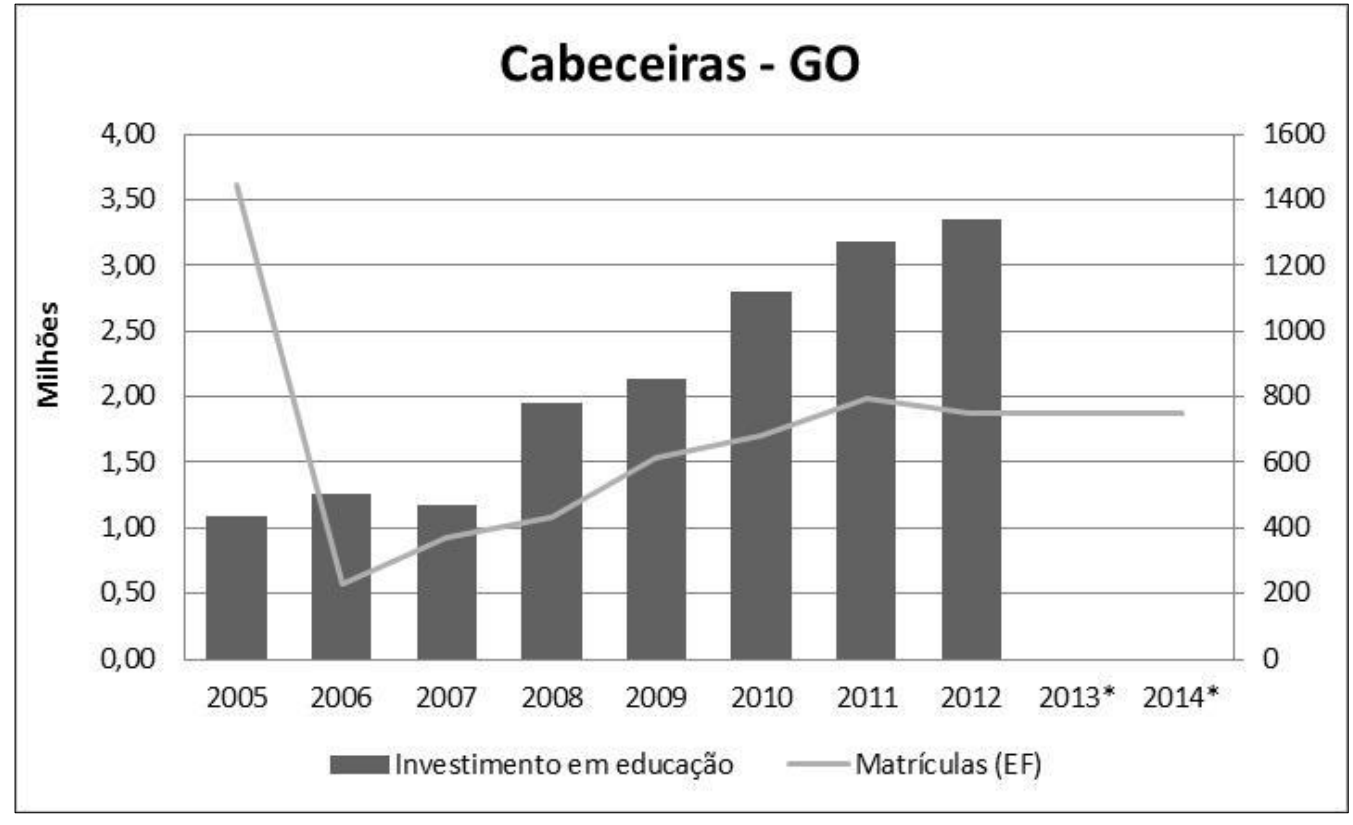

Fonte: SIOPE/FNDE (elaborado pelos autores).

Ao analisar o município de Formosa - GO, representado no Gráfico 3, verifica-se que este apresenta um comportamento de aumento do investimento em educação. Parte-se no ano de 2005 de um investimento de $\mathrm{R} \$ 13.458 .703,48$ para em 2013 , último ano em que o município transmitiu os dados por meio do SIOPE, investir $R \$ 49.212 .558,24$, representando um aumento de mais de $250 \%$ no 
gasto com o Ensino Fundamental. Em contrapartida, as matrículas nessa modalidade de ensino diminuíram em quase $30 \%$.

Conclui-se que o município de Formosa tem aumentado o investimento por aluno, sem, no entanto, melhorar a qualidade do Ensino Fundamental, o que pode ser verificado com os dados apresentados na Tabela 1, que mostra que nos anos de 2011 e 2013 a meta do IDEB projetada não foi atingida em nenhuma das etapas do Ensino Fundamental.

Gráfico 3 - Despesa empenhada e matrículas no EF no município de Formosa - GO

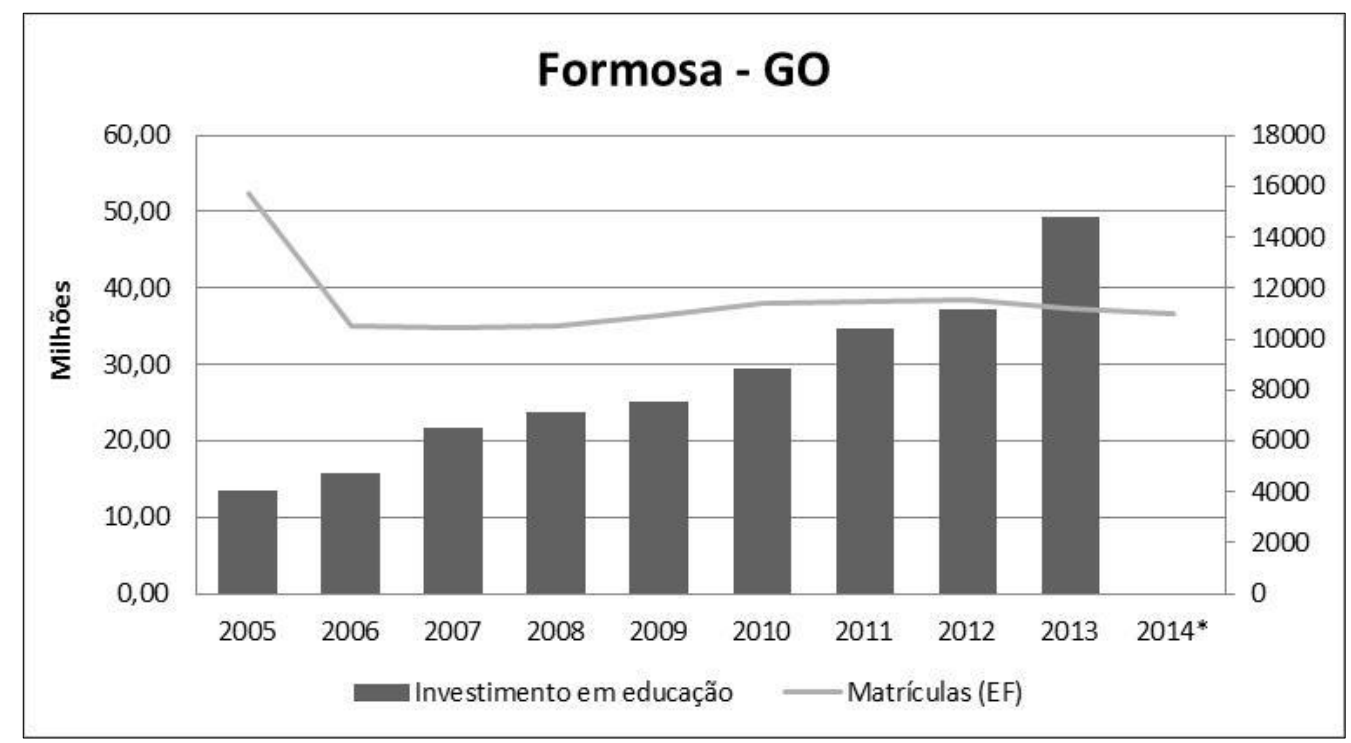

Fonte: SIOPE/FNDE (elaborado pelos autores).

No município de Mimoso de Goiás observa-se que o número de alunos matriculados na rede municipal do Ensino Fundamental não ultrapassa o quantitativo de 1000 alunos em nenhum ano pesquisado, conforme apresentado no Gráfico 4. 
Gráfico 4 - Despesa empenhada e matrículas no EF no município de Mimoso de Goiás - GO

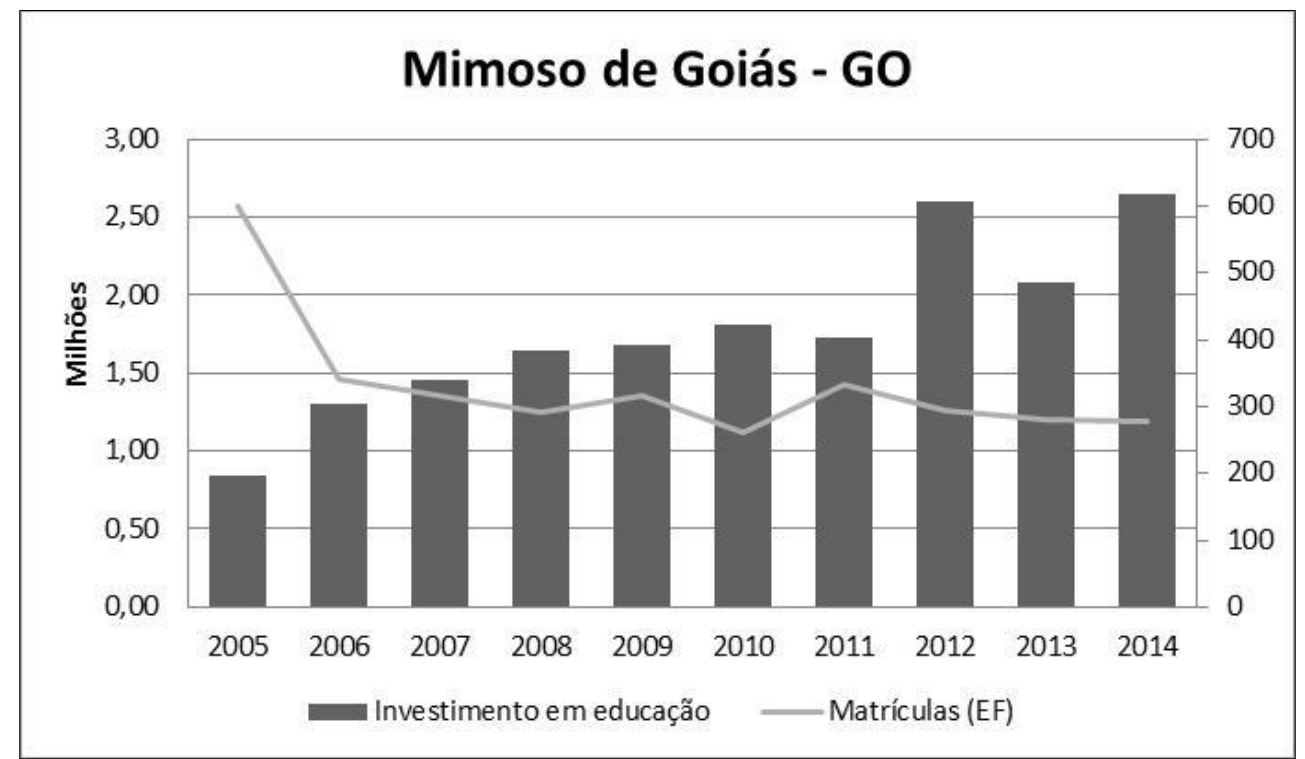

Fonte: SIOPE/FNDE (elaborado pelos autores).

O município tem aumentado os gastos nessa modalidade do ensino paralelamente à redução no número de matrículas (superior a $50 \%$ ). Comparando esses dados à nota do IDEB, verifica-se que a mesma passou de 3,9 em 2007 para 4,5 em 2013, conforme observado na Tabela 1.

A análise dos dados apresentados para o município de Mimoso de Goiás demonstra que o aumento do investimento em educação pode ser um dos variados fatores que tem contribuído para o aumento no índice que mede a educação básica no Brasil, nas séries iniciais do Ensino Fundamental.

Observa-se pelo Gráfico 5, que no município goiano de Padre Bernardo, nos anos de 2005 a 2007, os gastos com o Ensino Fundamental permaneceram praticamente estáveis enquanto que as matrículas tiveram uma ligeira queda. No ano de 2005 foram registradas 5.931 matrículas, em 2006, 5.112 matrículas e, em 2007, o registro foi de 5.089 alunos.

Nos anos seguintes o número de alunos matriculados no Ensino Fundamental permaneceu praticamente estável, chegando a menos de 5000 matrículas em 2014. Em contrapartida, o investimento nessa etapa da educação teve um aumento da ordem de 95\%. Com relação ao IDEB, o índice passou de 3,8 para 4,9 nas séries iniciais, e de 3,4 para 3,9 nas séries finais do Ensino Fundamental, tendo atingido a meta projetada. 
Gráfico 5 - Despesa empenhada e matrículas no EF no município de Padre Bernardo - GO

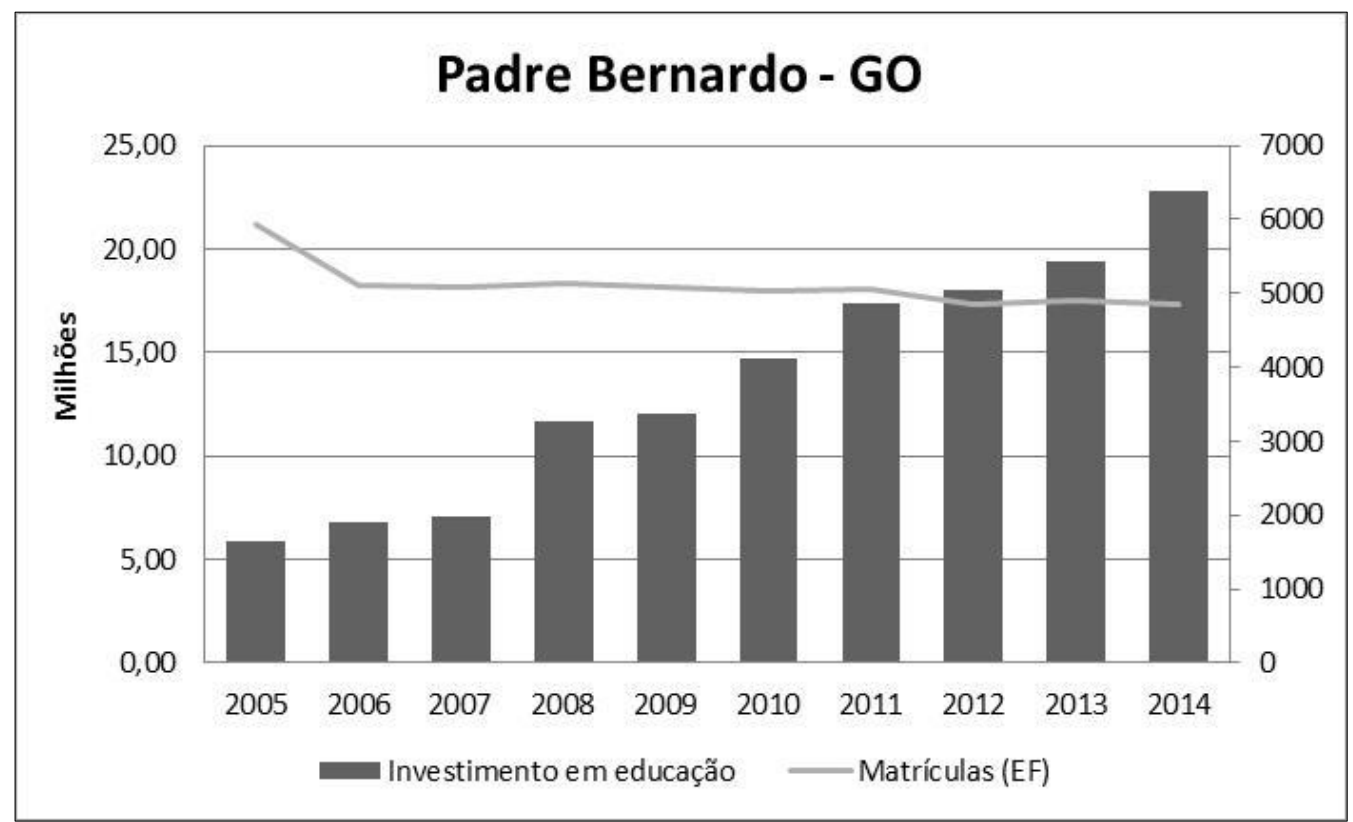

Fonte: SIOPE/FNDE (elaborado pelos autores).

Constata-se pelos dados apresentados que o indicador melhorou quando houve diminuição de alunos e aumento de despesa em educação no Ensino Fundamental.

Analisando o Gráfico 6, a seguir, referente à despesa empenhada e o número de matrículas no Ensino Fundamental para o munícipio de Planaltina, verifica-se que houve um aumento considerável no gasto com essa modalidade de ensino, alcançando, em 2014, quase $R \$ 60$ milhões. Na análise das matrículas constata-se que houve uma queda de 2005 para 2006 e, após, os registros permaneceram mais estáveis. 
Gráfico 6 - Despesa empenhada e matrículas no EF no município de Planaltina - GO

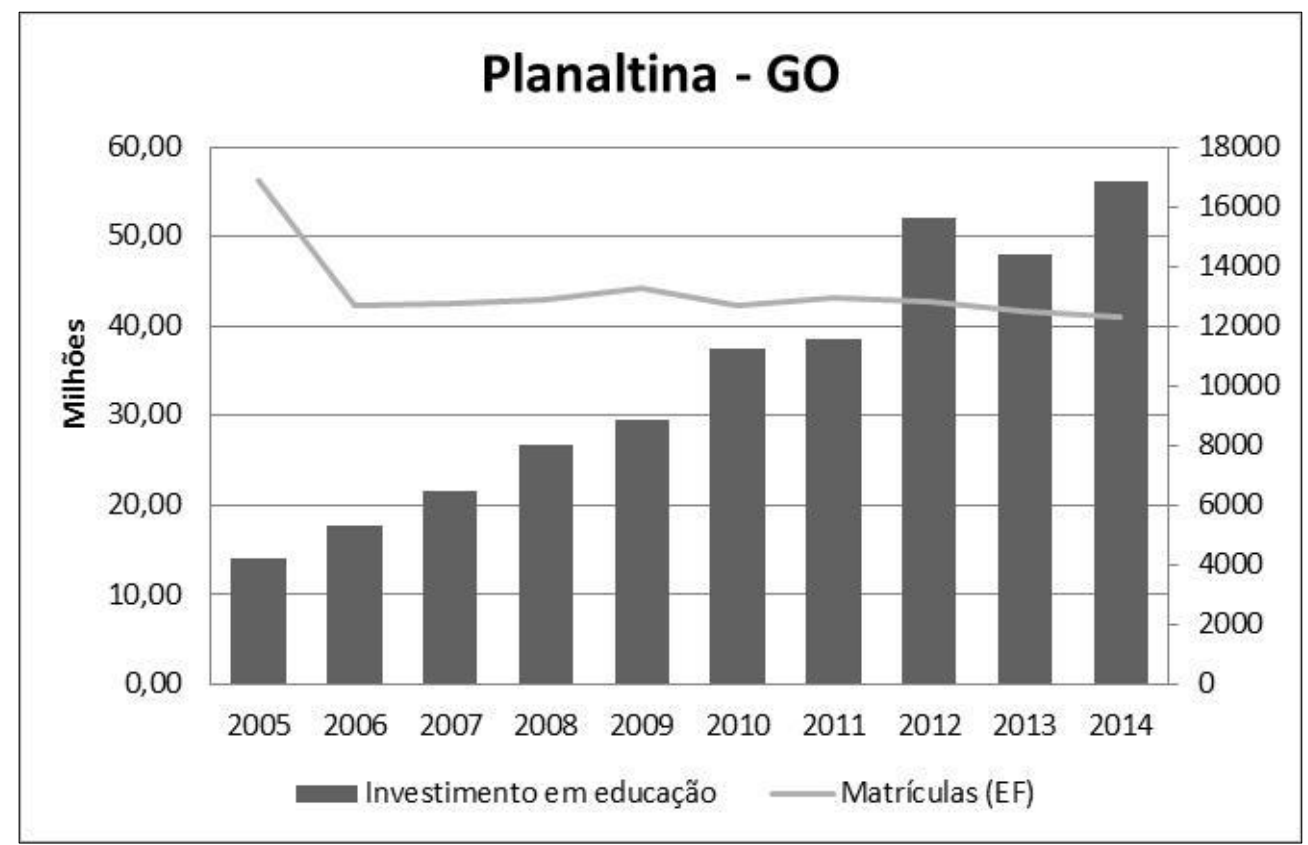

Fonte: SIOPE/FNDE (elaborado pelos autores).

Nesse cenário de aumento de investimento e estabilidade no número de matrículas espera-se um crescimento no índice que afere a melhoria da qualidade do ensino. Entretanto, em 2013, o munícipio de Planaltina não atingiu a meta do IDEB, mesmo tndo apresentado índice melhor que o anterior, conforme demonstrado na Tabela 1.

Ao comparar os dados do município de Vila Boa (Gráfico 7) com a Tabela 1 verifica-se que houve aumento do investimento nessa modalidade de ensino concomitante a redução nas matrículas.

No entanto, a meta do IDEB só foi atingida nos anos de 2009 e 2011, para as séries finais do Ensino Fundamental, não obtendo êxito o resultado para as séries iniciais desta etapa do ensino. Constata-se que para esse ente federado, o aumento do investimento em educação não proporcionou a melhoria da nota do IDEB. 
Gráfico 7 - Despesa empenhada e matrículas no EF no município de Vila Boa - GO

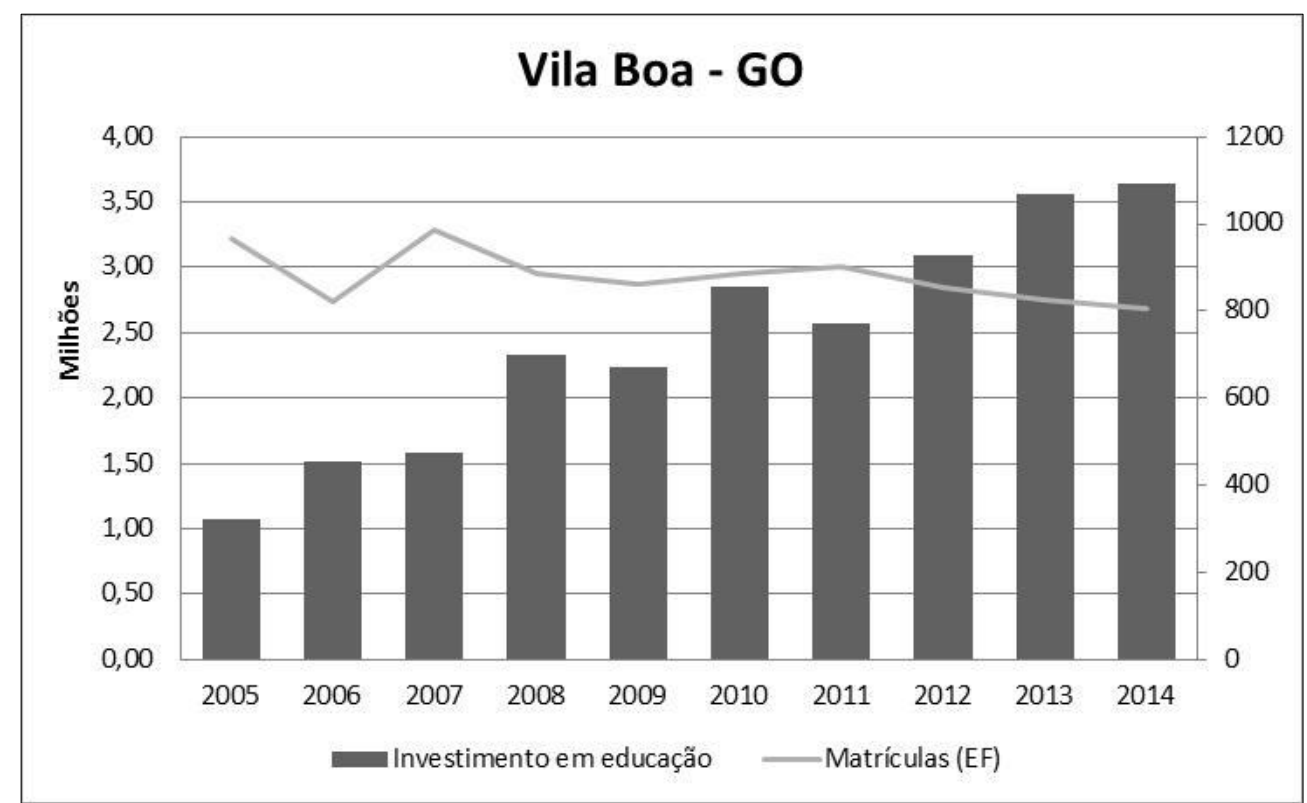

Fonte: SIOPE/FNDE (elaborado pelos autores).

O Distrito Federal é um ente federativo que possui competências e atribuições de natureza estadual e municipal. No campo educacional, Brasília possui atuação prioritária nas três modalidades da Educação Básica. Assim, são considerados os dados referentes a essa etapa da Educação Básica.

Gráfico 8 - Despesa empenhada e matrículas no EF no Distrito Federal - DF

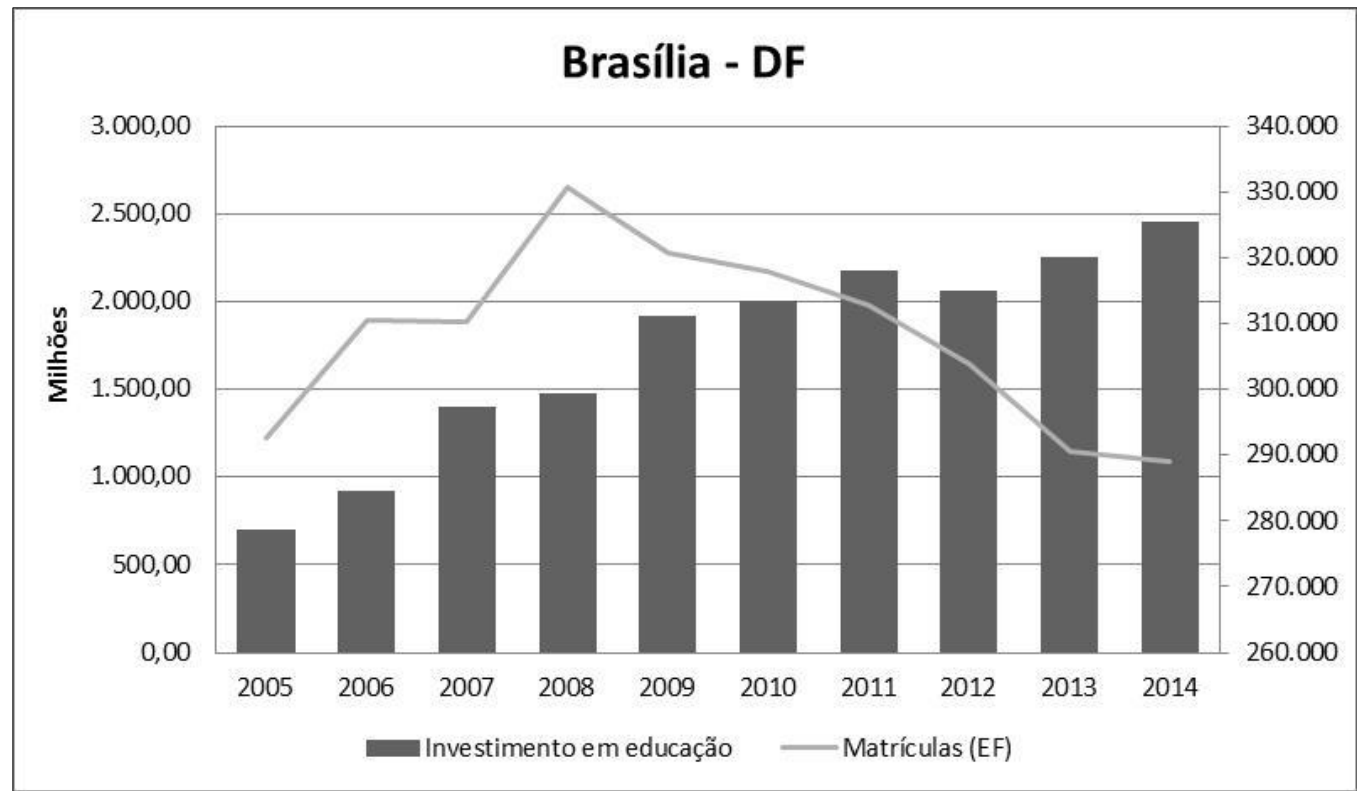

Fonte: SIOPE/FNDE (elaborado pelos autores). 
Nota-se pela análise do Gráfico 8 que houve um salto no número de matrículas no Ensino Fundamental nos anos de 2005 (292.649 alunos) a 2008 (330.733 alunos), seguida de uma redução, atingindo no ano de 2014, 289.086 matrículas, número inferior ao ano de 2005. Já, quando se analisa a despesa empenhada no Ensino Fundamental, verifica se tendência de crescimento de investimento, principalmente após o ano de 2008.

Quanto ao fator melhoria da nota no IDEB, o que se verifica com dados da Tabela 1, em relação às series iniciais do Ensino Fundamental, é um aumento nas notas de 2007 a 2011, quando o Distrito Federal partiu de um índice 4,8 para 5,4 . Com relação às séries finais, os índices são bem inferiores às séries iniciais parte-se de um índice de 3,5, em 2007, para 3,9 em 2011, e ainda registrase o indicador 3,8, em 2013, inferior à apuração anterior.

O município de Buritis, em Minas Gerais, aumentou consideravelmente o investimento na modalidade Ensino Fundamental, como se constata no Gráfico 9, superando 200\% de aumento de 2005 a 2014. Contrapondo a este aumento do gasto municipal no Ensino Fundamental, há queda de $44 \%$ no número de matrículas, o que favorece a disponibilidade de recursos para atendimento da rede municipal de ensino pelo município.

Gráfico 9 - Despesa empenhada e matrículas no EF no município de Buritis - MG

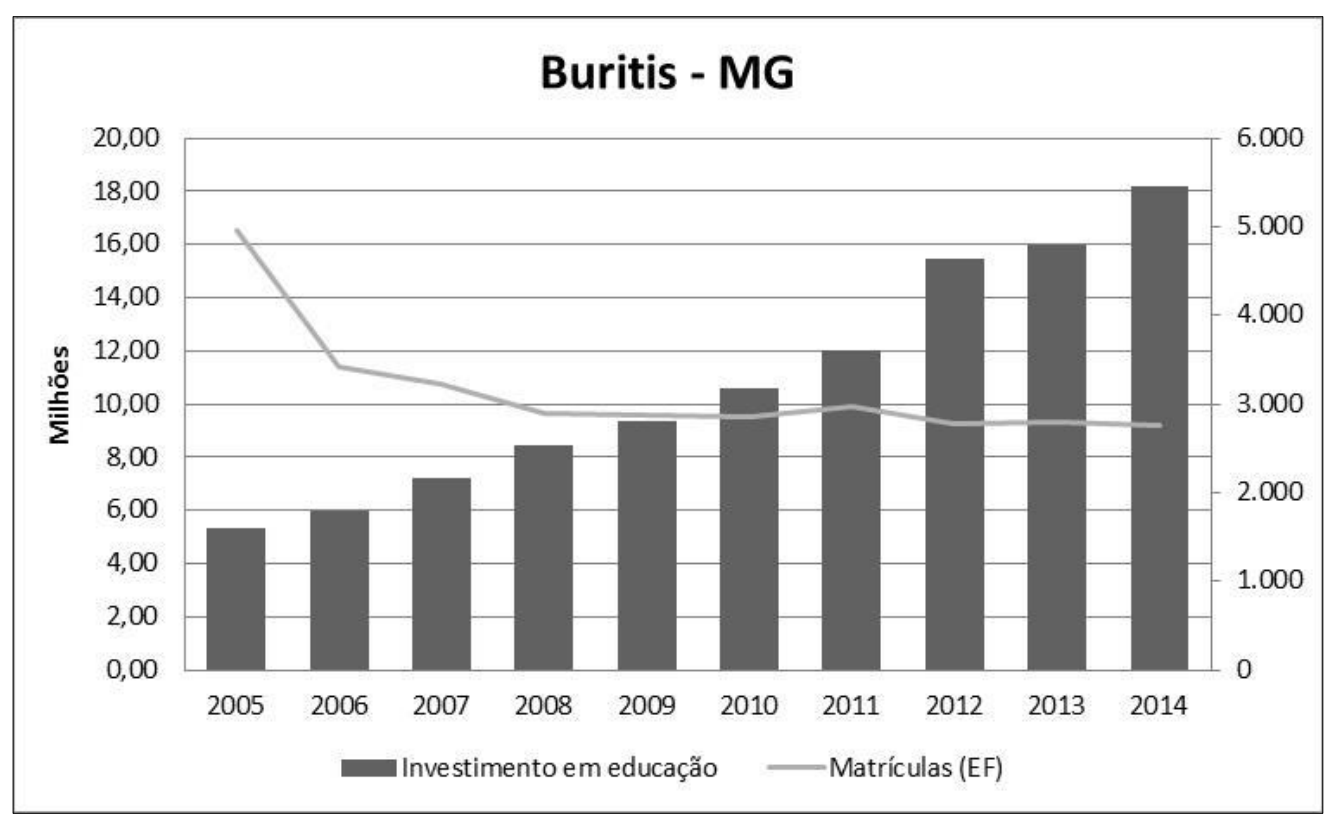

Fonte: SIOPE/FNDE (elaborado pelos autores).

$\mathrm{Na}$ análise da nota atingida pelo IDEB, desde 2007, o município de Buritis tem alcançado a meta projetada, de acordo com os dados constantes na Tabela 1, tanto nas séries iniciais quanto nas séries finais do Ensino Fundamental. Nas séries iniciais, parte-se de um índice de 3,5 para 5,6, considerando o período de 2005 a 2013, e, nas séries finais, temos o IDEB, neste mesmo período, de 3,1 para 4,4 . 
O município mineiro de Cabeceira Grande aumentou o investimento no Ensino Fundamental de 2005 a 2014, embora tenha apresentado comportamento irregular, com anos de acréscimo, como de 2007 para 2008, 2010 para 2011 e 2013 para 2014. Nos anos de 2008 para 2009, de 2011 para 2012, e de 2012 para 2013, houve uma diminuição no investimento no Ensino Fundamental, conforme observado no Gráfico 10.

O município atingiu as metas projetadas para as séries iniciais e finais do Ensino Fundamental nos anos de 2009, 2011 e 2013, de acordo com dados constantes da Tabela 1, alcançando o índice de 5,3 e 3,8, na última aferição do indicador.

Gráfico 10 - Despesa empenhada e matrículas no EF no município de Cabeceira Grande - MG

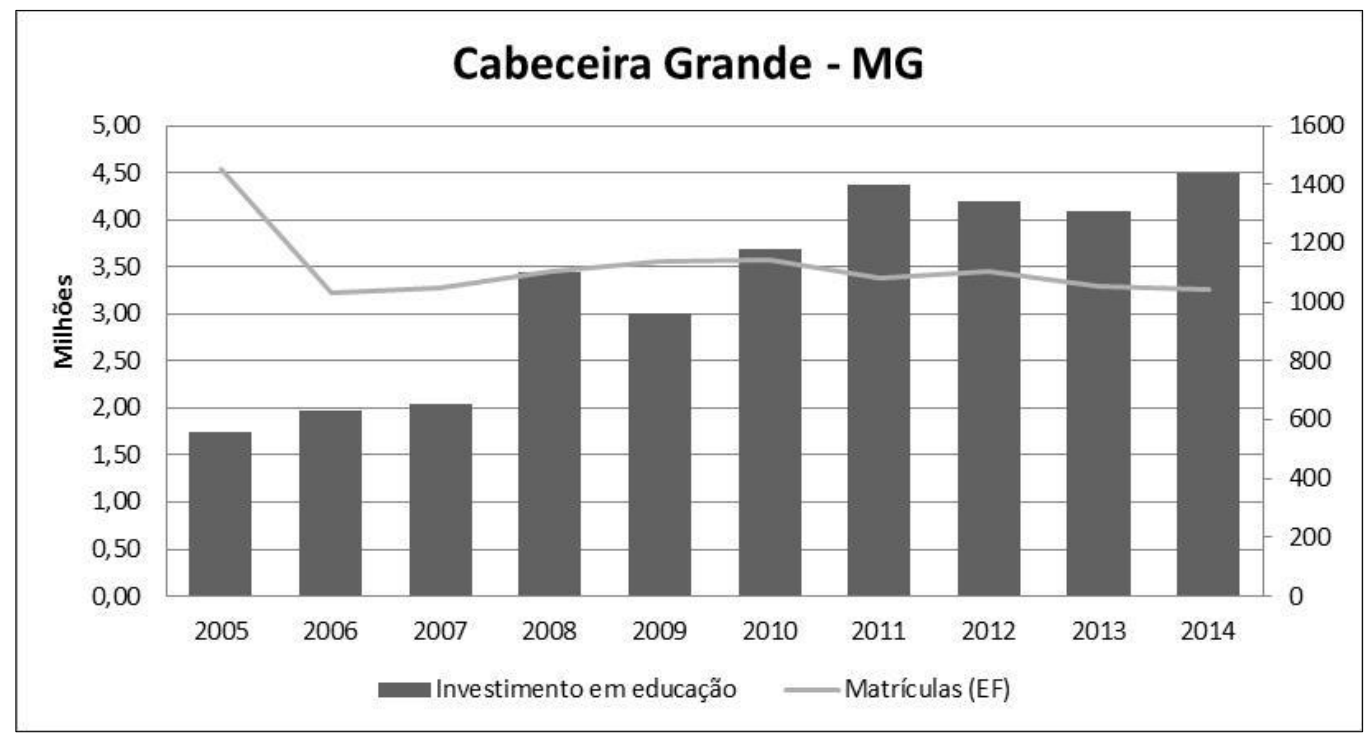

Fonte: SIOPE/FNDE (elaborado pelos autores).

No município de Unaí (Gráfico 11) observa-se que houve aumento na despesa empenhada com o Ensino Fundamental. Em 2005, o município possuía 12.426 alunos matriculados nessa modalidade de ensino e empenhou um valor de $\mathrm{R} \$ 10.746 .713,53$. No último ano analisado nesse artigo, as matrículas diminuíram para 4.614 alunos e, por outro lado, o investimento atingiu o valor de $\mathrm{R} \$ 25.078 .740,09$. Constata-se que enquanto as matrículas diminuíram cerca de $1 / 3$ nesses anos, o investimento mais que dobrou. 
Gráfico 11 - Despesa empenhada e matrículas no EF no município de Unaí - MG

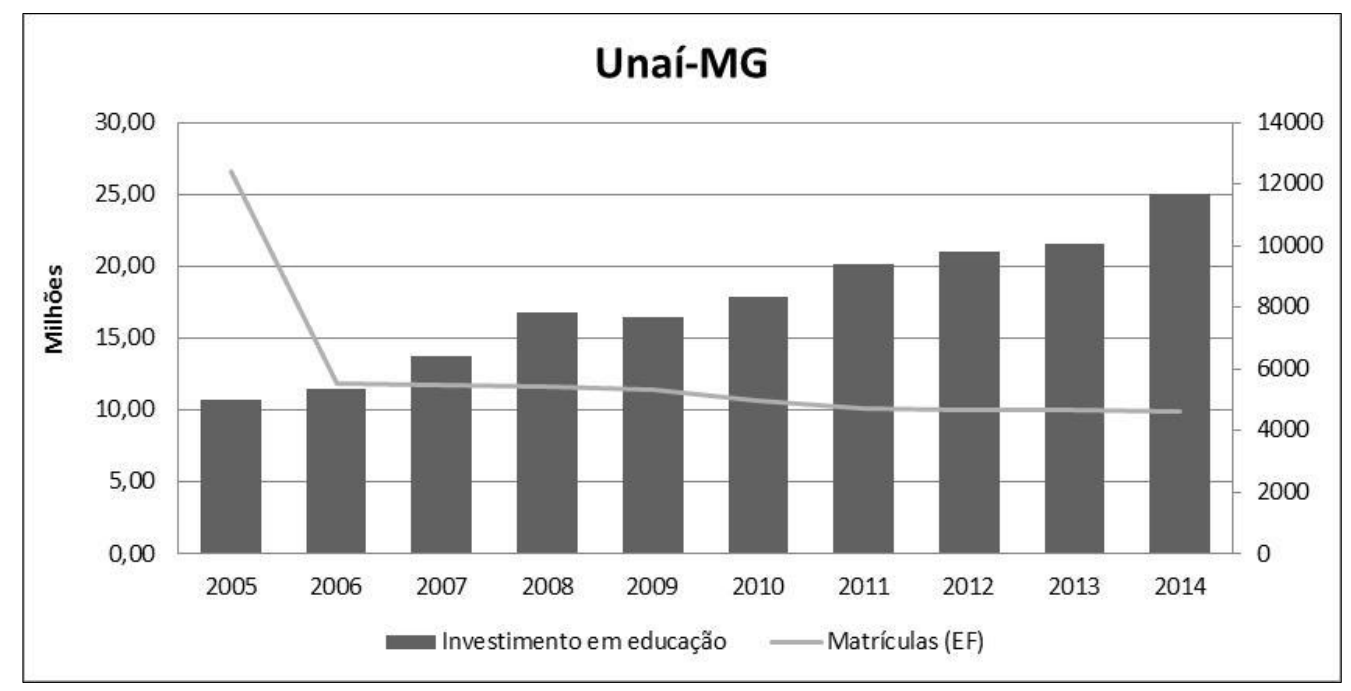

Fonte: SIOPE/FNDE (elaborado pelos autores).

Apesar do aumento do gasto educacional, a qualidade do ensino oferecido pelo município, medida pelo IDEB, não apresentou resultados satisfatórios para as séries finais do Ensino Fundamental nos anos de 2011 e 2013. A meta projetada do IDEB não foi atingida e, ainda, teve um decréscimo de 1 ponto. Em 2011 obteve a nota de 4,2 e em, 2013, o índice caiu para 4,1. Com relação às séries iniciais, observa-se que a meta foi atingida chegando ao índice de 5,3 em 2014.

\section{CONSIDERAÇÕES FINAIS}

O processo de redemocratização do Brasil, alcançado nas últimas décadas do século passado, culminou com a descentralização de políticas públicas sociais, em especial nas áreas da saúde e da educação.

$\mathrm{Na}$ educação, a implementação de políticas educacionais de acesso e permanência a todos os cidadãos à educação de qualidade alcançou a quase universalização do ensino fundamental, sem, no entanto, esse processo ser acompanhado da melhoria da qualidade do ensino.

A quase universalização da educação básica só se tornou uma realidade devido aos inúmeros esforços que resultaram na publicação de leis como a LDB, o FUNDEF e o FUNDEB, na década de 90 do século passado e início deste novo milênio, que tinha como principal objetivo tornar o acesso e a permanência de todos a uma educação básica de qualidade.

Todo esse aparato legal traz nas suas determinações e distribuição de competências o caráter descentralizador das políticas públicas educacionais em todos os aspectos, inclusive na questão do financiamento da educação básica. A Constituição de 1988 reforça o caráter supletivo da União de 
estabelecer as diretrizes e ficar a cargo dos entes subnacionais a execução da política educacional, a qualquer custo.

A presente pesquisa realizada nos onze entes federativos pertencentes ao Território das Águas Emendadas pode retratar a realidade vivenciada por outros munícipios e estados que formam outros territórios no Brasil.

A análise dos dados pesquisados no Território das Águas Emendadas mostra um aumento expressivo no investimento dos municípios e do Distrito Federal no Ensino Fundamental. Em todos os onze entes analisados a despesa empenhada nos últimos anos é superior à despesa empenhada em 2005. Cabe ressaltar que esse aumento nas despesas empenhadas é consequência de determinações legais de vinculação da receita de impostos a despesas com a educação e com a obrigatoriedade de aplicar um percentual mínimo de receitas de impostos na manutenção e desenvolvimento do ensino.

Observa-se também que o número de matrículas no Ensino Fundamental tem sofrido uma queda considerável no período de 2005 a 2014. Tendo em vista que estudos apontam para a universalização do ensino fundamental, a queda no número de matrículas pode ser resultado do novo perfil demográfico da população brasileira. Assim, o aumento do gasto por aluno por ano poderia contribuir para a melhoria da qualidade do ensino ofertado, uma vez que aumentam os investimentos ao mesmo tempo em que há uma queda no público-alvo a ser atendido. Trata-se de um cenário favorável à melhoria da qualidade da educação, se fosse esse, o único ou o principal fator responsável pela melhoria da qualidade do ensino.

Diante do exposto e da pesquisa realizada, pode se deduzir que o processo de descentralização da política de financiamento educacional e o investimento em educação são importantes para a melhoria da qualidade do ensino, entretanto ele deve ser acompanhado de políticas de valorização dos profissionais da educação, de melhoria dos cursos de formação de professores, de melhoria na infraestrutura das escolas, de melhoria de condições para a permanência e continuidade dos estudos, e isto envolve políticas de cunho social, e ainda de uma gestão eficiente dos recursos destinados à educação. Assim, na realidade em que se vive a educação brasileira, pode se afirmar que o principal problema não consiste na falta de investimento, mas na forma como todo este recurso está sendo aplicado.

\section{REFERÊNCIAS}

1. AMARAL, N. C. do. (2001); "Um novo Fundef? As idéias de Anísio Teixeira" Revista Educação e Sociedade, v.22, n. 75, p.227-229. Disponível em: <http://www.scielo.br/scielo.php?pid=S010173302001000200013\&script=sci_abstract\&tlng=pt >.

2. AMARAL, N. C. do (2012); "Para compreender o financiamento da educação básica no Brasil." Brasília: Liber Livro. 
3. ARRETCHE, M. T. S. (1996); "Mitos da descentralização: mais democracia e eficiência nas políticas públicas?" Revista Brasileira de Ciências Sociais, n.31, ano 11. Disponível em: < http://www.anpocs.org.br/portal/publicacoes/rbcs_00_31/rbcs31_03.htm>.

4. BRASIL. Constituição da República Federativa do Brasil de 1988. Brasília.

5 . Lei de Diretrizes e Base da Educação Nacional, Lei no 9.394, de 20 de dezembro de 1996. Brasília. Disponível em: <http://portal.mec.gov.br/arquivos/pdf/ldb.pdf>. Lei $\mathrm{n}^{\circ}$. 9.424, de 24 de dezembro de 1996. Regulamenta o Fundo de Manutenção e Desenvolvimento da Educação Básica e de Valorização dos Profissionais da Educação FUNDEB. Brasília, DF. Disponível em:<http://www.planalto.gov.br/ccivil_03/leis/l9424.htm>. Manual de Orientação do FUNDEF. Fundo Nacional de Desenvolvimento da Educação, Ministério da Educação. Brasília, DF. 2004. Disponível em: < http://portal.mec.gov.br/arquivos/pdf/manual.pdf>. Lei $n^{\circ}$. 11.494, de 20 de junho de 2007. Fundo de Manutenção e Desenvolvimento do Ensino Fundamental e de Valorização do Magistério - FUNDEF. Brasília, DF Disponível em:< http://www.planalto.gov.br/ccivil_03/_ato2007-2010/2007/lei//11494.htm>. . Manual de Orientação do FUNDEB. Fundo Nacional de Desenvolvimento da Educação, Ministério da Educação. Brasília, DF. 2008. Disponível em: < ftp://ftp.fnde.gov.br/web/siope/leis/manual_orientacao_fundeb.pdf>.

10. CASTRO J. A. de. (2007); "Financiamento e gasto público na educação básica no Brasil: 19952005". Educação e Sociedade, Campinas, vol. 28, n. 100 - Especial, p. 857-876. Disponível em < http://www.cedes.unicamp.br>.

11. FARAH, M. F. S. (2001); "Parcerias, novos arranjos institucionais e políticas públicas no nível local de governo". Revista de Administração Pública, v.35, n.1, p.119-144. Disponível em < http://bibliotecadigital.fgv.br/ojs/index.php/rap/article/viewFile/6364/4949>.

12. GOUVEIA, A. B.; SOUZA, Â. R. de e TAVARES, T. M. (2009); "O Ideb e as políticas educacionais na região metropolitana de Curitiba". Estudos em Avaliação Educacional, v. 20, São Paulo. Disponível em < http://publicacoes.fcc.org.br/ojs/index.php/eae/article/view/2058/2016 >.

GRAEF, A. (2010); "Articulação federativa na prestação de serviços sociais no Brasil". Revista do Serviço Público. 61(1) p.35-66, Brasília. Disponível em < http://repositorio.enap.gov.br/handle/1/1653>. 
14. PINTO, J. M. de R. (2007); "A política recente de fundos para o financiamento da educação e seus efeitos no pacto federativo". Educação e Sociedade, Campinas, vol. 28, n. 100 - Especial, p. 877-897. Disponível em: < http://www.cedes.unicamp.br >.

15. VELOSO, F. et ali (orgs). (2009) “Educação Básica no Brasil”: construindo o país do futuro. Editora Campus.

lara da Paixão Corrêa Teixeira

Mestre em Gestão Pública pela Universidade de Brasília.

\section{Andre Nunes}

Doutor em Economia, Professor da Universidade de Brasília.

\section{Alexandre Nascimento de Almeida}

Doutor em Engenharia Florestal pela Universidade Federal do Paraná, Professor da Universidade de Brasília.

\section{Como citar este documento:}

TEIXEIRA, lara da Paixão Corrêa; NUNES, Andre; ALMEIDA, Alexandre Nascimento de. O processo de descentralização e o financiamento das políticas públicas educacionais. Reflexão e Ação, Santa Cruz do Sul, v. 27, n. 2, abr. 2019. ISSN 1982-9949. Disponível em: <https://online.unisc.br/seer/index.php/reflex/article/view/8875>. Acesso em: doi:https://doi.org/10.17058/rea.v27i2.8875. 